\title{
Association of cardiac autonomic modulation with physical and clinical features of young people with type 1 diabetes
}

\author{
Anne K. F. Silva, ${ }^{1}$ Diego G. D. Christofaro, ${ }^{2}$ Franciele M. Vanderlei, ${ }^{3}$ Marianne P. C. R. Barbosa, ${ }^{1}$ \\ David M. Garner, ${ }^{4}$ Luiz C. M. Vanderlei ${ }^{3}$ \\ ${ }^{1}$ Faculty of Science and Technology, Universidade Estadual Paulista; ${ }^{2}$ Department of Physical Education, Faculty of \\ Science and Technology, Universidade Estadual Paulista; ${ }^{3}$ Department of Physical Therapy, Faculty of Science and \\ Technology, Universidade Estadual Paulista, Presidente Prudente, São Paulo, Brazil; ${ }^{4}$ Cardiorespiratory Research Group, \\ Department of Biological and Medical Sciences, Faculty of Health and Life Sciences, Oxford Brookes University, Oxford, \\ United Kingdom
}

\begin{abstract}
Objective: The objective of this study was to verify possible associations between heart rate variability indices and physical activity, body composition, and metabolic and cardiovascular parameters in individuals with type 1 diabetes. Method: A total of 39 young patients with type 1 diabetes were included. Body composition, physical activity, cardiovascular parameters, and metabolic parameters were assessed. For the heart rate variability analysis, heart rate was recorded beat-by-beat using a Polar S810i heart rate monitor for 30 minutes, with the volunteers in the supine position; subsequently, the following indices were considered: standard deviation of all normal RR intervals; root-mean square of differences between adjacent normal RR intervals in a time interval; percentage of adjacent $\mathrm{RR}$ intervals with a difference of duration $>50 \mathrm{~ms}$; high frequency component in milliseconds squared; high frequency component in normalised units; standard deviation of the instantaneous variability beat-to-beat; and standard deviation of the long-term variability. The association between the heart rate variability indices and independent variables was verified through linear regression in unadjusted and adjusted models (considering gender and age). The statistical significance was set at $5 \%$ and the confidence interval at $95 \%$. Results: High values of at-rest heart rate were associated with reduced parasympathetic activity and global heart rate variability, and higher values of waist-to-hip ratio were related to lower parasympathetic activity, independent of age or gender. Conclusion: For young patients with type 1 diabetes, increases in at-rest heart rate values are associated with reduced parasympathetic activity and global heart rate variability, whereas higher waist-to-hip ratio values are related to lower parasympathetic activity, both independent of age and gender.
\end{abstract}

Keywords: Diabetes mellitus type 1 autonomic nervous system; risk factors; heart rate; young adult

Received: 30 July 2015; Accepted: 7 January 2016; First published online: 16 March 2016

$\mathrm{T}$ YPE 1 DiABETES MELLITUS IS AN AUTOIMMUNE disease resulting from the self-destruction of pancreatic $\beta$ cells and subsequent insulin deficiency, which favours chronic hyperglycaemia. It is an important public health problem. ${ }^{1}$ The incidence

Correspondence to: L. C. M. Vanderlei, Faculdade de Ciências e Tecnologia UNESP - Universidade Estadual Paulista, Programa de Pós Graduação em Fisioterapia, Avenida Roberto Simonsen, 305, 19060-900 Presidente Prudente, São Paulo, Brazil. Tel: +55 183229 5819; Fax: +55 183223 4519; E-mail: lcmvanderlei@fct.unesp.br of type 1 diabetes has increased globally. ${ }^{2}$ In addition, it is appearing increasingly in younger individuals. ${ }^{3}$

Individuals with type 1 diabetes may present complications arising from microvascular and macrovascular alterations that lead to dysfunction and insufficiency in different organs. ${ }^{1}$ The incidence of complications in type 1 diabetes is directly related to glycaemic control. ${ }^{4}$ It is increased by the presence of cardiovascular risk factors, such as a sedentary lifestyle, smoking, obesity, hypertension, and hyperlipidaemia. ${ }^{5}$ 
Among the complications induced by type 1 diabetes, cardiac autonomic neuropathy stands out, as it is present in $25 \%$ of those with type 1 diabetes ${ }^{6}$ and is closely related to the increased mortality rate observed in these individuals. ${ }^{7}$

This type of neuropathy is a result of damage to the autonomic nerve fibres that innervate the heart and blood vessels, causing abnormalities in the control of heart rate and cardiovascular dynamics ${ }^{8}$ and subsequent problems in circulation and blood distribution.

Heart rate variability is a simple, non-invasive method that describes the oscillations in the intervals between consecutive heart beats ( $R R$ intervals), related to the influences of the autonomic nervous system on the sinus node. ${ }^{9}$ It has been recommended by the American Diabetes Association ${ }^{10}$ for assessing the presence of autonomic alterations in patients with diabetes.

Individuals with type 1 diabetes present reductions in global heart rate variability when compared with healthy individuals in various age groups. ${ }^{11-14}$ Reduction in both autonomic components ${ }^{13,14}$ or reduction in the parasympathetic component with increases in the sympathetic component, ${ }^{15}$ observed through heart rate variability indices, have also been related to type 1 diabetes.

By correlating cardiovascular risk factors with linear indices of heart rate variability in type 1 diabetic patients, Jaiswall et $\mathrm{al}^{15}$ observed that older age, female gender, and high levels of low-density lipoprotein cholesterol and triglycerides were associated with reduced heart rate variability. Reduction in heart rate variability was also observed in individuals with type 1 diabetes who presented high blood pressure and body mass index values and low levels of physical activity. ${ }^{16}$ In addition, studies have revealed that both individuals with altered glycaemia and diabetics present a reduction in the parasympathetic component ${ }^{17,18}$ and that in type 2 diabetics some factors such as systolic blood pressure and at-rest heart rate are associated with reduced heart rate variability. ${ }^{19}$

As discussed, several factors may be related to alterations in the autonomic modulation of individuals with diabetes. Nevertheless, the majority of studies ${ }^{16-18}$ have focussed on patients above 30 years of age. Consequently, as the occurrence of type 1 diabetes is becoming increasingly frequent in individuals below 30 years of age and variables related to body composition and cardiovascular parameters may be associated with autonomic alterations in diabetics, studies are required that aim to evaluate the influence of these factors on the autonomic modulation of young patients with type 1 diabetes. Such studies are vital as they allow identification of possible physical and clinical characteristics that may influence the dynamics of the autonomic nervous system in these individuals, and consequently the development of more appropriate health interventions.

For that reason, this study aimed to evaluate the associations between heart rate variability indices and physical activity practise, body composition, and metabolic and cardiovascular parameters in young individuals with type 1 diabetes. The hypothesis proposed that in individuals with type 1 diabetes, associations would be found between clinical and physical characteristics and heart rate variability indices.

\section{Method}

Casuistry

Volunteers for this study were recruited from the data bank of Basic Units of Health and through direct contact with physicians specialising in the area of endocrinology, in the city of Presidente Prudente, Sao Paulo, Brazil. The final cohort consisted of 43 young individuals aged 18-30 years, of both genders (20 men and 23 women; mean age $21.82 \pm$ 5.07 years), with a clinical diagnosis of type 1 diabetes (age since diagnosis $11.20 \pm 6.01$ years).

Young individuals who satisfied the following conditions were included in the study: clinical diagnosis of type 1 diabetes mellitus, confirmed by blood test and medical diagnosis (type 1 diabetes mellitus group); not having cardiorespiratory diseases; and not being a smoker and/or alcoholic. Volunteers were disqualified if they were found to have $<95 \%$ sinus beats on prolonged RR interval recordings. ${ }^{20}$

All individuals were informed about the objectives and procedures of the study. After agreeing to participate, they signed an informed consent form. All study procedures followed the Declaration of Helsinki and were approved by the Research Ethics Committee of the Faculty of Science and Technology - Universidade Estadual Paulista, Presidente Prudente (CAAE: 22530813.9.0000.5402/Protocol: 417.031).

\section{Data collection}

Data collection was undertaken in a room with temperature between 21 and $23^{\circ} \mathrm{C}$ and humidity of 40-60\%, between 13:00 and 18:00 to minimise the influences of circadian rhythm. ${ }^{21}$ The assessments were performed individually. The volunteers were instructed not to consume alcoholic beverages and/or autonomic nervous system stimulants such as coffee, tea or chocolate in the 24 hours preceding the assessment.

Initially, data were collected on age, gender, time since first diagnosis, and use of medications. Next, physical, clinical, and autonomic evaluations were executed, as described below. After completing these procedures, the volunteers were free to leave. 


\section{Physical and clinical assessments}

Following this, cardiovascular parameters, body composition, physical activity practise, and random blood glucose levels of the volunteers were evaluated.

\section{Cardiovascular parameters}

Blood pressure. Verification of systolic and diastolic blood pressure was undertaken indirectly, using a stethoscope (Littman, Saint Paul, Minnesota, United States of America) and an aneroid sphygmomanometer (Welch Allyn - Tycos, New York, United States of America) on the left arm of the patient while sitting, using the criteria established by the VI Brazilian Guidelines on Hypertension. ${ }^{22}$

Heart rate. The volunteers were told to remain at rest for 5 minutes in the sitting position, and after this period the value of heart rate was recorded using a Polar S810i (Polar Electro, Kempele, Finland) heart rate monitor.

\section{Body composition}

For estimation of body composition, measurements of mass, height, waist circumference, and hip circumference were performed, followed by percentage fat measurement using bioimpedance.

For anthropometric analysis, the volunteers were instructed to remain barefoot and wear light clothing (pants and shirt). Height was measured using a stadiometer (Sanny, São Paulo, Brazil), in the standing position, with the feet parallel, and body mass distributed evenly between them throughout the measurement. Measurement of body mass was performed using a digital scale (Welmy R/I 200; Welmy, Santa Bárbara D'Oeste/SP, Brazil). From the data, the body mass index $=$ mass $/$ height ${ }^{2}\left(\mathrm{~kg} / \mathrm{m}^{2}\right)$ was calculated according to the Brazilian Guidelines for Obesity. ${ }^{23}$

The measurements of waist circumference - that is, the smallest abdominal perimeter situated between the last rib and the higher iliac crest - and hip circumference - that is, the greatest gluteal portion at the height of the greater trochanter - were obtained with the help of an inelastic tape measure (Sanny) with the volunteers standing, arms abducted. The waist-hip ratio was calculated from these measurements. ${ }^{24}$

The body fat percentage was calculated using Bioimpedance, Maltron BF 906, Body Fat Analyzer (Maltron, United Kingdom) equipment with the individual in the supine position on a non-conductive surface, with no contact with metallic objects, the lower limbs abducted at $45^{\circ}$, and the upper limbs at $30^{\circ}$ to avoid contact between the limbs and the trunk. Before this assessment, the volunteers were instructed not to practise intense physical activity for 8 hours, suspend the use of diuretics for 24 hours, and not to ingest liquids, alcohol, or consume foods for 4 hours. ${ }^{25}$

To complete the analysis, the electrodes were placed, with a minimum distance of $5 \mathrm{~cm}$ between them. Sterilisation with alcohol was undertaken at the following locations: the base of the third finger, just above the wrist joint, near the styloid process of the right hand, at the base of the third toe on the right foot, and just above the ankle joint, between the medial and lateral malleolus. ${ }^{26}$

\section{Physical activity practise}

Physical activity practise was assessed by applying the International Physical Activity Questionnaire, short version. ${ }^{27}$ This questionnaire consists of questions that investigate physical activity performed during a normal week and is divided into four different domains: physical activity as a means of transport and activities at work, home, and during relaxation. The International Physical Activity Questionnaire allows classification of individuals into the following subgroups: very active, active, insufficiently active, and sedentary.

\section{Random blood glycaemia}

Random blood glycaemia was calculated through a fingertip puncture examination, where the sample obtained was placed on a One-touch ultra dipstick (Johnson \& Johnson Medical, Brazil) and analysed using a One-touch ultra glucometer (Johnson \& Johnson Medical). The volunteers were not constrained by an eating or fasting period.

\section{Autonomic assessment}

For autonomic evaluation, after the initial instructions, a recording strap was positioned on the chest of the volunteers in the sternum region, and the Polar S810i (Polar Electro, Finland) heart rate receiver was placed on the wrist. This equipment had been previously validated to capture beat-to-beat heart rate, and the resulting data were used for the analysis of heart rate variability. ${ }^{28}$ After insertion of the strap and the monitor, the volunteers were placed in the supine position on a stretcher where they remained at rest for 30 minutes. The volunteers were instructed to remain at rest, awake, spontaneously breathe, and to avoid conversations during data collection. After data collection of the autonomic modulation, the volunteers were free to leave.

For analysis of heart rate variability indices, heart rate was recorded beat-to-beat throughout the experimental protocol; 1000 consecutive RR intervals were chosen from the period with the greatest signal stability after digital filtering by Polar Precision Performance SW software (version 4.01.029), 
complemented by manual filtering to eliminate premature ectopic beats and artefacts; only series with $>95 \%$ sinus beats were included in the study ${ }^{20}$

For heart rate variability analysis, linear indices in the time and frequency domains and non-linear indices were applied. ${ }^{\text {? }}$ The heart rate variability analysis in the time domain was undertaken through standard deviation of all normal RR intervals, rootmean square of differences between adjacent normal $R R$ intervals in a time interval, and percentage of adjacent $\mathrm{RR}$ intervals with a difference of duration $>50 \mathrm{~ms}$ indices. As for heart rate variability analysis in the frequency domain, the high frequency spectral components $(0.15-0.40 \mathrm{~Hz})$ were used, in milliseconds squared and normalised units. The spectral analysis was calculated using Fast Fourier Transform.

The non-linear indices used were extracted from the Poincaré plot. The Poincaré plot is a graphical representation of a time series and allows each RR interval to be plotted versus the previous interval defining a point on the plot. ${ }^{29}$ For assessment of the plot, the following indices were calculated: standard deviation of the instantaneous variability beat-to-beat and standard deviation of the long-term variability.

All indices were evaluated using heart rate variability analysis software - Kubios HRV version 2.0 ${ }^{30}$ (Biosignal Analysis and Medical Image Group, Department of Physics, University of Kuopio, Finland).

\section{Data analysis}

Normality of data was verified by the KolmogorovSmirnov test. The variables that supported the Gaussian distribution model are presented as mean and standard deviation. The non-normally distributed variables are shown as median and interquartile range.

The correlations among the heart rate variability indices and independent variables - resting heart rate, systolic and diastolic blood pressures, percentage body fat, body mass index, waist-to-hip ratio, random blood glycaemia, and physical activity practise - were verified through Linear Regression in unadjusted and adjusted models, considering the gender and age of the patients. The statistical significance was set at 5\% and the confidence interval at $95 \%$. The programme applied for statistical analysis was Statistical Package for Social Sciences - version 15.0 (SPSS Inc., Chicago, Illinois, United States of America).

\section{Results}

While undertaking this study, data sets of 43 volunteers with type 1 diabetes were analysed. From this group, four volunteers $(9.3 \%)$ were disqualified for having an error in the series of RR intervals $>5 \%$. Thus, the final sample consisted of 39 young people with type 1 diabetes (19 men and 20 women; $\mathrm{p}=0.384$ ).

In Table 1, the general characteristics of the volunteers are presented. Among them, three were obese - two individuals with obesity degree II and one with obesity degree III - and the time since diagnosis of diabetes varied between 3 to 26 years. All the volunteers were insulin dependent and maintained their normal treatment on the assessment day, in addition to which 15 of them (38.46\%) were taking other drugs besides insulin. From this group, five (12.82\%) used medications to control blood pressure, eight $(20.51 \%)$ for thyroid disorders, three $(7.69 \%)$ for cholesterol control, five $(12.82 \%)$ for contraceptive use, and eight $(20.51 \%)$ for various reasons such as rhinitis, peripheral neuropathy, and epilepsy.

Table 2 illustrates the association of the heart rate variability indices with the variables: heart rate (at rest), systolic blood pressure, and diastolic blood pressure, with and without adjustment for gender and age. It can be seen that independent of age or gender, the heart rate (at rest) variable was significantly associated with the following six calculated variables: standard deviation of all normal RR intervals recorded in a time interval expressed in milliseconds, root-mean square of differences between adjacent normal RR intervals in a time interval expressed in milliseconds, the highfrequency component in milliseconds squared, the percentage of adjacent $R R$ intervals with a difference of duration $>50 \mathrm{~ms}$, the standard deviation of the instantaneous variability beat-to-beat, and the standard deviation of the long-term variability $(p \leqslant 0.005)$.

Table 3 demonstrates the analysis of the association between the heart rate variability indices and the following variables: body fat, body mass index, and waist-to-hip ratio of the volunteers analysed, with and without adjustment for gender and age. It is significant that the waist-hip ratio was the only

Table 1. Characteristics of volunteers with type 1 diabetes mellitus.

\begin{tabular}{lc}
\hline Variables & $\begin{array}{c}\text { Type 1 diabetes } \\
\text { mellitus (39) }\end{array}$ \\
\hline Age (years)** & $21.00(7.00)$ \\
Body weight $(\mathrm{kg})^{*}$ & $73.54(15.31)$ \\
Height $(\mathrm{m})^{*}$ & $1.73(0.17)$ \\
Body mass index $\left(\mathrm{Kg} / \mathrm{m}^{2}\right)^{* *}$ & $24.19(5.84)$ \\
Waist-to-hip ratio $(\mathrm{cm})^{*}$ & $0.80(0.10)$ \\
Systolic blood pressure $(\mathrm{mmHg}) * *$ & $110.00(10.00)$ \\
Diastolic blood pressure $(\mathrm{mmHg})^{* *}$ & $60.00(10.00)$ \\
Heart rate $(\mathrm{bpm})^{*}$ & $80.00(16.00)$ \\
Random blood glycaemia $(\mathrm{mg} / \mathrm{dl})^{* *}$ & $162.00(168.00)$ \\
Body fat $(\%)^{*}$ & $26.00(9.60)$ \\
Weekly physical activity $(\mathrm{minutes}) * *$ & $280.00(510.00)$ \\
Diagnostic time* & $11.71(5.99)$ \\
\hline
\end{tabular}

* Mean (standard deviation)

*** Median (interquartile range) 
Table 2. Correlation of heart rate variability indices with the variables heart rate at rest, systolic blood pressure, and diastolic blood pressure with and without adjustment for age and sex in young people with type 1 diabetes mellitus.

\begin{tabular}{|c|c|c|c|c|c|c|c|c|c|c|c|c|}
\hline & \multicolumn{4}{|l|}{ Heart rate at rest } & \multicolumn{4}{|c|}{ Systolic blood pressure } & \multicolumn{4}{|c|}{$\underline{\text { Diastolic blood pressure }}$} \\
\hline & \multicolumn{2}{|l|}{ Without adjustment } & \multicolumn{2}{|l|}{ Adjusted (sex and age) } & \multicolumn{2}{|l|}{ Without adjustment } & \multicolumn{2}{|c|}{ Adjusted (sex and age) } & \multicolumn{2}{|l|}{ Without adjustment } & \multicolumn{2}{|l|}{ Adjusted (sex and age) } \\
\hline & $\beta 95 \% \mathrm{CI}$ & $\mathrm{p}$ & $\beta 95 \% \mathrm{CI}$ & $\mathrm{p}$ & $\beta 95 \% \mathrm{CI}$ & $\mathrm{p}$ & $\beta 95 \% \mathrm{CI}$ & $\mathrm{p}$ & $\beta 95 \% \mathrm{CI}$ & $\mathrm{p}$ & $\beta 95 \% \mathrm{CI}$ & $\mathrm{p}$ \\
\hline rMSSD & $-0.83(-1.32 ;-0.34)$ & 0.001 & $-0.90(-1.39 ;-0.41)$ & 0.001 & $-0.09(-0.56 ; 0.38)$ & 0.705 & $0.06(-0.46 ; 0.59)$ & 0.797 & $-0.34(-0.85 ; 0.16)$ & 0.179 & $-0.23(-0.79 ; 0.32)$ & 0.402 \\
\hline SDNN & $-0.95(-1.50 ;-0.40)$ & 0.001 & $-0.95(-1.50 ;-0.40)$ & 0.001 & $-0.01(-0.54 ; 0.52)$ & 0.980 & $0.16(-0.42 ; 0.74)$ & 0.580 & $-0.43(-1.03 ; 1.10)$ & 1.10 & $-0.35(-0.97 ; 0.26)$ & 0.248 \\
\hline $\mathrm{HF}\left(\mathrm{ms}^{2}\right)$ & $-22.24(-37.26 ;-7.21)$ & 0.005 & $-22.11(-36.91 ;-7.31)$ & 0.005 & $-1.34(-15.4 ; 12.8)$ & 0.849 & $3.41(-11.8 ; 18.6)$ & 0.652 & $-7.96(-23.30 ; 0.31)$ & 0.300 & $-3.99(-20.41 ; 12.41)$ & 0.624 \\
\hline $\mathrm{HF}(\mathrm{nu})$ & $-0.28(-0.75 ; 0.19)$ & 0.234 & $-0.37(-0.85 ; 0.10)$ & 0.121 & $-0.09(-0.49 ; 0.31)$ & 0.639 & $-0.05(-0.50 ; 0.39)$ & 0.801 & $-0.19(-0.63 ; 0.24)$ & 0.379 & $-0.18(-0.66 ; 0.29)$ & 0.436 \\
\hline pNN50 & $-6.31(-10.93 ;-1.70)$ & 0.009 & $-7.14(-11.74 ;-2.55)$ & 0.003 & $-0.03(-4.32 ; 4.25)$ & 0.987 & $1.46(-3.26 ; 6.19)$ & 0.532 & $-2.24(-6.89 ; 2.41)$ & 0.335 & $-1.22(-6.34 ; 3.87)$ & 0.627 \\
\hline SD1 & $-0.59(-0.93 ;-0.24)$ & 0.001 & $-0.64(-0.98 ;-0.29)$ & 0.001 & $-0.06(-0.40 ; 0.27)$ & 0.706 & $0.04(-0.32 ; 0.42)$ & 0.796 & $-0.24(-0.60 ; 0.11)$ & 0.177 & $-0.16(-0.53 ; 0.26)$ & 0.399 \\
\hline SD2 & $-1.20(-1.92 ;-0.48)$ & 0.002 & $-1.18(-1.90 ;-0.46)$ & 0.002 & $0.01(-0.68 ; 0.70)$ & 0.977 & $0.22(-0.52 ; 0.97)$ & 0.546 & $-0.61(1.35 ; 0.13)$ & 0.104 & $-0.48(-0.12 ; 0.31)$ & 0.227 \\
\hline
\end{tabular}

$\mathrm{HF}\left(\mathrm{ms}^{2}\right)=$ high-frequency component in milliseconds squared; $\mathrm{HF}(\mathrm{nu})=$ high-frequency component in normalised units; pNN $50=$ percentage of adjacent RR intervals with a difference of duration $>50 \mathrm{~ms}$; $\mathrm{rMSSD}=$ root-mean square of differences between adjacent normal RR intervals in a time interval expressed in milliseconds; SD1 = standard deviation of the instantaneous variability beat-to-beat; $\mathrm{SD} 2=$ standard deviation of the long-term variability; $\mathrm{SDNN}=$ standard deviation of all normal $\mathrm{RR}$ intervals recorded in a time interval expressed in milliseconds

Bold values are significant at $\mathrm{p}<0.05$

Table 3. Correlation of heart rate variability indices with the variables body fat, body mass index and waist-to-hip ratio with and without adjustment for age and sex in young people with type 1 diabetes mellitus.

\begin{tabular}{|c|c|c|c|c|c|c|c|c|c|c|c|c|}
\hline & \multicolumn{4}{|l|}{ Body fat (\%) } & \multicolumn{4}{|l|}{ Body mass index } & \multicolumn{4}{|l|}{ Waist-to-hip ratio } \\
\hline & \multicolumn{2}{|l|}{ Without adjustment } & \multicolumn{2}{|l|}{ Adjusted (sex and age) } & \multicolumn{2}{|l|}{ Without adjustment } & \multicolumn{2}{|l|}{ Adjusted (sex and age) } & \multicolumn{2}{|l|}{ Without adjustment } & \multicolumn{2}{|l|}{ Adjusted (sex and age) } \\
\hline & $\beta 95 \% \mathrm{CI}$ & $\mathrm{p}$ & $\beta 95 \% \mathrm{CI}$ & $\mathrm{p}$ & $\beta 95 \% \mathrm{CI}$ & $\mathrm{p}$ & $\beta 95 \% \mathrm{CI}$ & $\mathrm{p}$ & $\beta 95 \% \mathrm{CI}$ & $\mathrm{p}$ & $\beta 95 \% \mathrm{CI}$ & $\mathrm{p}$ \\
\hline rMSSD & $-1.25(-0.72 ; 0.47)$ & 0.676 & $-0.05(-0.75 ; 0.65)$ & 0.886 & $-0.15(-1.36 ; 1.06)$ & 0.802 & $0.03(-1.21 ; 1.27)$ & 0.962 & $-63.24(-140.04 ; 13.75)$ & 0.104 & $-65.90(-171.23 ; 39.41)$ & 0.212 \\
\hline SDNN & $-0.40(-1.07 ; 0.25)$ & 0.222 & $-0.19(-0.97 ; 0.58)$ & 0.619 & $-0.27(-1.64 ; 1.08)$ & 0.685 & $-0.03(-1.41 ; 1.34)$ & 0.965 & $-41.16(-129.86 ; 47.53)$ & 0.353 & $-60.37(-78.08 ; 57.33)$ & 0.305 \\
\hline $\mathrm{HF}\left(\mathrm{ms}^{2}\right)$ & $-4.23(-22.12 ; 13.65)$ & 0.634 & $4.48(-15.89 ; 24.25)$ & 0.658 & $10.27(-25.57 ; 46.11)$ & 0.565 & $18.25(-17.16 ; 53.66)$ & 0.303 & $-216.41(\infty)$ & 0.854 & $84.47(\infty)$ & 0.956 \\
\hline HF (nu) & $-0.09(-0.61 ; 0.41)$ & 0.697 & $-0.36(-0.94 ; 0.22)$ & 0.221 & $-0.88(-1.87 ; 0.10)$ & 0.080 & $-0.83(-1.94 ; 0.08)$ & 0.070 & $-76.09(-138.92 ;-13.26)$ & 0.019 & $-90.81(-177.37 ;-4.24)$ & 0.040 \\
\hline pNN50 & $0.04(-5.37 ; 5.47)$ & 0.986 & $0.28(-0.607 ; 6.63)$ & 0.928 & $0.80(-10.09 ; 11.70)$ & 0.882 & $2.17(-1.94 ; 0.08)$ & 0.695 & $-579.11(\infty)$ & 0.097 & $-512.06(\infty)$ & 0.284 \\
\hline SD1 & $-0.08(-0.51 ; 0.33)$ & 0.676 & $-0.03(-0.56 ; 0.46)$ & 0.887 & $-0.10(-0.96 ; 0.75)$ & 0.800 & $0.02(-0.85 ; 0.89)$ & 0.964 & -44.66 (-98.99; 9.66) & 0.104 & $-46.55(-121.06 ; 27.96)$ & 0.213 \\
\hline SD2 & $-0.59(-1.45 ; 0.26)$ & 0.170 & $-0.28(-1.29 ; 0.71)$ & 0.566 & $-0.39(-2.16 ; 1.08)$ & 0.657 & $-0.06(-1.84 ; 1.71)$ & 0.939 & $-43.66(-159.41 ; 72.08)$ & 0.450 & $-71.43(-223.96 ; 81.08)$ & 0.348 \\
\hline
\end{tabular}

$\mathrm{HF}\left(\mathrm{ms}^{2}\right)=$ high-frequency component in milliseconds squared; $\mathrm{HF}(\mathrm{nu})=$ high-frequency component in normalised units; pNN50=percentage of adjacent RR intervals with a difference of duration $>50$ ms; $\mathrm{rMSSD}=$ root-mean square of differences between adjacent normal R R intervals in a time interval expressed in milliseconds; $\mathrm{SD} 1=$ standard deviation of the instantaneous variability beat-to-beat; $\mathrm{SD} 2=$ standard deviation of the long-term variability; SDNN = standard deviation of all normal RR intervals recorded in a time interval expressed in milliseconds

Bold values are significant at $\mathrm{p}<0.05$ 
Table 4. Correlation of heart rate variability indices with the variables random blood glycaemia and physical activity with and without adjustment for age and sex in young people with type 1 diabetes mellitus.

\begin{tabular}{|c|c|c|c|c|c|c|c|c|}
\hline & \multicolumn{4}{|c|}{ Random blood glycaemia } & \multicolumn{4}{|c|}{ Physical activity } \\
\hline & \multicolumn{2}{|c|}{ Without adjustment } & \multicolumn{2}{|c|}{ Adjusted (sex and age) } & \multicolumn{2}{|c|}{ Without adjustment } & \multicolumn{2}{|c|}{$\underline{\text { Adjusted (sex and age) }}$} \\
\hline & $\beta 95 \% \mathrm{CI}$ & $\mathrm{p}$ & $\beta 95 \% \mathrm{CI}$ & $\mathrm{p}$ & $\beta 95 \% \mathrm{CI}$ & $\mathrm{p}$ & $\beta 95 \% \mathrm{CI}$ & $\mathrm{p}$ \\
\hline rMSSD & $\begin{array}{l}-0.02 \\
-0.08 ; 0.03\end{array}$ & 0.344 & $\begin{array}{l}-0.01 \\
-0.07 ; 0.04\end{array}$ & 0.543 & $\begin{array}{l}-0.00 \\
-0.01 ; 0.00\end{array}$ & 0.686 & $\begin{array}{l}-0.00 \\
-0.01 ; 0.00\end{array}$ & 0.495 \\
\hline SDNN & $\begin{array}{l}-0.02 \\
-0.08 ; 0.04\end{array}$ & 0.510 & $\begin{array}{l}-0.01 \\
-0.07 ; 0.05\end{array}$ & 0.754 & $\begin{array}{l}-0.02 \\
-0.08 ; 0.04\end{array}$ & 0.510 & $\begin{array}{l}-0.01 \\
-0.01 ; 0.00\end{array}$ & 0.356 \\
\hline $\mathrm{HF}\left(\mathrm{ms}^{2}\right)$ & $\begin{array}{l}-0.71 \\
-2.46 ; 0.103\end{array}$ & 0.410 & $\begin{array}{l}-0.39 \\
-2.16 ; 1.37\end{array}$ & 0.652 & $\begin{array}{l}-0.02 \\
-0.33 ; 0.29\end{array}$ & 0.889 & $\begin{array}{l}-0.10 \\
-0.42 ; 0.20\end{array}$ & 0.497 \\
\hline HF (nu) & $\begin{array}{l}-0.00 \\
-0.05 ; 0.04\end{array}$ & 0.875 & $\begin{array}{l}-0.00 \\
-0.05 ; 0.05\end{array}$ & 0.931 & $\begin{array}{l}-0.00 \\
-0.01 ; 0.00\end{array}$ & 0.254 & $\begin{array}{l}-0.00 \\
-0.01 ; 0.00\end{array}$ & 0.334 \\
\hline pNN50 & $\begin{array}{l}-0.22 \\
-0.75 ; 0.30\end{array}$ & 0.403 & $\begin{array}{l}-0.14 \\
-0.69 ; 0.40\end{array}$ & 0.591 & $\begin{array}{l}-0.03 \\
-0.02 ; 0.06\end{array}$ & 0.488 & $\begin{array}{l}-0.04 \\
-0.13 ; 0.05\end{array}$ & 0.394 \\
\hline SD1 & $\begin{array}{l}-0.02 \\
-0.06 ; 0.02\end{array}$ & 0.346 & $\begin{array}{l}-0.01 \\
-0.05 ; 0.03\end{array}$ & 0.545 & $\begin{array}{l}-0.00 \\
0.00 ; 0.00\end{array}$ & 0.686 & $\begin{array}{l}-0.00 \\
-0.00 ; 0.01\end{array}$ & 0.496 \\
\hline SD2 & $\begin{array}{l}-0.02 \\
-0.11 ; 0.06\end{array}$ & 0.561 & $\begin{array}{l}-0.01 \\
-0.09 ; 0.07\end{array}$ & 0.810 & $\begin{array}{l}-0.00 \\
-0.01 ; 0.01\end{array}$ & 0.696 & $\begin{array}{l}-0.00 \\
-0.02 ; 0.00\end{array}$ & 0.347 \\
\hline
\end{tabular}

$\mathrm{HF}\left(\mathrm{ms}^{2}\right)=$ high-frequency component in milliseconds squared; HF $(\mathrm{nu})=$ high-frequency component in normalised units; pNN50 = percentage of adjacent RR intervals with a difference of duration $>50 \mathrm{~ms} ; \mathrm{rMSSD}=$ root-mean square of differences between adjacent normal RR intervals in a time interval expressed in milliseconds; SD1 = standard deviation of the instantaneous variability beat-to-beat; SD2 = standard deviation of the long-term variability; $\mathrm{SDNN}=$ standard deviation of all normal RR intervals recorded in a time interval expressed in milliseconds

variable associated with heart rate variability and only for the high-frequency component in normalised units index, independent of adjustment for gender or age $(\mathrm{p}=0.040)$.

Table 4 illustrates the connection of heart rate variability indices with the following variables: random blood glycaemia and physical activity, with and without adjustment for gender and age. No significant associations were observed between the variables and evaluated indices even after the adjustments.

\section{Discussion}

In the present study, it was revealed that in young people with type 1 diabetes, high values of at rest heart rate are associated with reduced parasympathetic activity - root-mean square of differences between adjacent normal RR intervals in a time interval expressed in milliseconds, high frequency component in milliseconds squared, percentage of adjacent RR intervals with a difference of duration $>50 \mathrm{~ms}$, and standard deviation of the instantaneous variability beat-to-beat - and global heart rate variability - standard deviation of all normal RR intervals recorded in a time interval expressed in milliseconds and standard deviation of the long-term variability - and that higher values of waist-to-hip ratio are related with lower parasympathetic activity - high-frequency component in normalised units - independent of age or gender. The variables systolic blood pressure, diastolic blood pressure, body mass index, body fat, random blood glycaemia, and physical activity practise demonstrated no significant associations with the evaluated heart rate variability indices, before or after the adjustments.

Young patients with type 1 diabetes, independent of age or gender, were found to have higher heart rate at rest values associated with parasympathetic activity and global variability. Similar results were observed by Cambri et al, ${ }^{19}$ who demonstrated that a reduction in the standard deviation of the instantaneous variability beat-to-beat index was correlated negatively $(r=-0.73)$ with at-rest heart rate values in middle-aged adults with type 2 diabetes, indicating that the lower the parasympathetic tone the greater the at-rest heart rate values. Similar results were found by Fronchetti et al, ${ }^{31}$ wherein the standard deviation of the instantaneous variability beat-to-beat index was negatively related to heart rate at rest in healthy young individuals.

Heart rate is influenced by vagal activity, which maintains low values at rest, ${ }^{32}$ whereas its increase is the result of increased action of the sympathetic pathway and/or reduced parasympathetic activity that is, vagal inhibition. ${ }^{33}$ The autonomic modifications found in this study, which manifest as reduced heart rate variability, are an indicator of abnormal and insufficient adaptation of the autonomic nervous system, ${ }^{9}$ which, in patients already at risk, such as those with diabetes, can be particularly hazardous. ${ }^{18}$ 
Several studies have revealed that high heart rate at rest increases the risk of cardiovascular mortality ${ }^{34,35}$ both in healthy individuals ${ }^{36}$ and in type 2 diabetics. ${ }^{37}$ Recent findings have also shown that increased heart rate at rest is associated with an increased risk of developing type 2 diabetes in both men and women. ${ }^{38}$

According to Tarvainen et $\mathrm{al},{ }^{39}$ prolonged hyperglycaemia can be allied with a moderate increase in heart rate at rest and decreased heart rate variability - root-mean square of differences between adjacent normal RR intervals in a time interval expressed in milliseconds and the high-frequency component. Another aspect stated by the authors to be strongly associated with reduced heart rate variability is the duration of the diabetes - the most significant association being present in the first 5-10 years of the disease, pointing to a decrease in parasympathetic activity. ${ }^{39}$

Another factor observed to be associated with heart rate variability was the waist-to-hip ratio, which is considered an important measure in predicting cardiovascular risk. ${ }^{40}$ In patients with type 2 diabetes, the waist-to-hip ratio has been shown to be slightly more accurate for predicting cardiovascular risk than body mass index. ${ }^{41}$ An increase in visceral adipose tissue, measured by the waist-to-hip ratio, is associated with higher metabolic alterations, including decreased glucose tolerance and reduced insulin levels, both of which are risk factors for type 2 diabetes and cardiovascular disease. ${ }^{40}$ Another factor is the release of inflammatory substances by adipose tissue that could also contribute to alterations in autonomic modulation. $^{42}$

In addition, independent of age or gender, an increase in the waist-to-hip ratio is associated with reduced parasympathetic activity - high-frequency component in normalised units - in young patients with type 1 diabetes, suggesting that higher abdominal adiposity is related to a reduction in vagal modulation, and therefore a higher risk of mortality and cardiovascular and metabolic complications in individuals with type 1 diabetes.

As the waist-to-hip ratio and at-rest heart rate are related to parasympathetic autonomic derangement and possibly to the prognosis of individuals with type 1 diabetes, measures such as an appropriate diet, ${ }^{43}$ performing physical activity, ${ }^{44}$ and glycaemic control $^{45}$ should all be encouraged to reduce and prevent the metabolic consequences of this disease state. ${ }^{46}$

The regular practise of physical activity as an addition to treatment for type 1 diabetes can assist in adequate glycaemic control, ${ }^{47}$ reducing the daily dose of insulin, decreasing the risk of complications associated with diabetes, ${ }^{48}$ and controlling cardiovascular risk factors. ${ }^{47}$ Besides, physical exercise in adolescents with type 1 diabetes can contribute to increased vagal control and slight sympathetic reduction. ${ }^{49}$ Yet, in this study, no association was observed between higher levels of physical activity practise and increases in autonomic modulation. A possible reason for this may have been the method used for measuring physical activity. In this study, physical activity was assessed using a questionnaire, which can incur potential memory bias in selfreporting some activities.

In addition, the present investigation evaluated the association between heart rate variability indices and the following variables: diastolic blood pressure, systolic blood pressure, body mass index, body fat, random blood glycaemia, and physical activity. Interestingly, no association was found between these variables and the heart rate variability indices used in the study, even after adjustments. Conversely, Colhoun et $\mathrm{al}^{16}$ found links between heart rate variability indices and variables such as blood pressure, high body mass index, and low levels of physical activity when contrasting men and women with type 1 diabetes.

Generally, the participants in this study presented characteristics within the normal standards (Table 1), which could explain the non-existence of associations with heart rate variability indices. This is similar to the findings of Jaiswal et $\mathrm{al}^{15}$ where no association was found between variables such as age, gender, body mass index, and diastolic blood pressure with the standard deviation of all normal RR intervals recorded in a time interval expressed in milliseconds, the rootmean square of differences between adjacent normal $\mathrm{RR}$ intervals in a time interval expressed in milliseconds, the high-frequency component in normalised units, low frequency in normalised units, and the lowfrequency component and high-frequency component ratio in young patients with type 1 diabetes.

Individual diabetics may be predisposed to various complications that could be exacerbated in the presence of cardiovascular risk factors. ${ }^{5}$ According to the literature, these factors are associated with modifications in autonomic nervous system behaviour. ${ }^{15,16,19,31}$ Nonetheless, the literature still lacks the necessary studies that focus on the assessment of the association of risk factors to heart rate variability in young patients with type 1 diabetes.

There are limitations to the present study. For example, the presence of obesity in three of the volunteers and the variation of the time interval between the diagnosis of type 1 diabetes and the study period of between 3 and 26 years may have prejudiced the results. Moreover, some volunteers administered medications that may influence autonomic behaviour, such as those to combat epilepsy and rhinitis; however, the tracings obtained from these volunteers were carefully evaluated and 
demonstrated good quality, with values of heart rate variability indices very similar to those of the volunteers who did not use any medications other than insulin. Another weakness concerns the assessment of physical activity through a questionnaire. It is suggested that future studies use more accurate evaluation methods such as tri-axial accelerometry. Moreover, the cross-sectional nature of the study only permitted the association of the data; the dose response relationship between autonomic modulation and the risk factors analysed could not be determined.

A novel aspect of this research was the exploration of these associations in patients with type 1 diabetes, as the majority of studies have evaluated type 2 diabetics. $^{19,39,41}$ Furthermore, using heart rate variability assessment is more sensitive than only using the relationship between at-rest heart rate and cardiovascular risk factors, noting that in this study the at-rest heart rate was also treated as an independent variable.

In summary, from the results obtained in this study we can conclude that in young patients with type 1 diabetes, increases in at rest heart rate values are associated with reduced parasympathetic activity and global heart rate variability, whilst higher waist-tohip ratio values are related to lower parasympathetic activity, both independent of age and gender. These results support professionals that get involved with treatment of young patients with type 1 diabetes. In this sense, it addresses the importance of indirect monitoring of cardiovascular health state, through periodic measurements of at rest heart rate and waistto-hip ratio. Also, it allows drawing a profile of these variables during treatment, to identify changes related to the autonomic behavior and to motive changes in the lifestyle to complement the drug treatment, such as physical activity and healthy eating habits. These changes could reduce the negative impact of the disease in the quality of life of this population.

\section{Acknowledgements}

The authors thank FAPESP (Support Foundation for Research of São Paulo State) for financial support for this study (Case Number: 2013/19055-0).

Authors' contribution: A.K.F.S. and M.P.C.R.B. participated in the acquisition of data. A.K.F.S., M.P.C.R.B., F.M.V., D.G.D.C., D.M.G., and L.C.M.V. participated in the revision of the manuscript. A.K.F.S., M.P.C.R.B., F.M.V., D.G.D.C., and L.C.M.V. determined the design, interpreted the data, and drafted the manuscript. All the authors read and gave final approval to the version submitted for publication.

\section{Financial Support}

The study was funded by the Support Foundation for Research of São Paulo State.

\section{Conflicts of Interest}

None.

\section{Ethical Standards}

The authors assert that all study procedures followed the Declaration of Helsinki and were approved by the Research Ethics Committee of the Faculty of Science and Technology - FCT/UNESP, Presidente Prudente (CAAE: 22530813.9.0000.5402/Protocol: 417.031).

\section{References}

1. Brazilian Society of Diabetes. Guidelines of the Brazilian Society of Diabetes: 2013-2014. AC Farmacêutica, São Paulo, 2014.

2. Maahs DM, West NA, Lawrence JM, Mayer-Davis EJ. Epidemiology of type 1 diabetes. Endocrinol Metab Clin North Am 2010; 39: 481-497.

3. Fradkin JE, Rodgers GP. Diabetes research: a perspective from the National Institute of Diabetes and Digestive and Kidney Diseases. Diabetes J 2013; 62: 320-326.

4. Menke A, Orchard TJ, Imperatore G, Bullard KM, Mayer-Davis E, Cowie CC. The prevalence of type 1 diabetes in the United States. Epidemiology 2013; 24: 773-774.

5. Daneman D. Early diabetes-related complications in adolescents. Horm Res 2005; 63: 75-85.

6. Vinik AI, Ziegler D. Diabetic cardiovascular autonomic neuropathy. Circulation 2007; 115: 387-397.

7. Maser RE, Mitchell BD, Vinik AI, Freeman R. The association between cardiovascular autonomic neuropathy and mortality in individuals with diabetes - a meta-analysis. Diabetes Care 2003; 26: 1895-1901.

8. Khatoon N, Kumar BS, Abdul M. Cardiovascular autonomic neuropathy in patients with diabetes mellitus. Int J Pharma Bio Sci 2010; $1: 1$.

9. Vanderlei LCM, Pastre CM, Hoshi RA, Carvalho TD, Godoy MF. Basic notions of heart rate variability and its clinical applicability. Rev Bras Cir Cardiovasc 2009; 24: 205-217.

10. Boulton AJ, Vinik AI, Arezzo JC, et al. Diabetic neuropathies: a statement by the American Diabetes Association. Diabetes Care 2005; 28: 956-962.

11. Guzik P, Piskorski J, Contreras P, Migliaro ER. Asymmetrical properties of heart rate variability in type 1 diabetes. Clin Auton Res 2010; 20: 255-257.

12. Javorka M, Javorková J, Tonhajzerová I, Calkovska A, Javorka K. Heart rate variability in young patients with diabetes mellitus and healthy subjects explored by Poincaré and sequence plots. Clin Physiol Funct Imaging 2005; 25: 119-127.

13. Chessa M, Butera G, Lanza GA, et al. Role of heart rate variability in the early diagnosis of diabetic autonomic neuropathy in children. Herz 2002; 27: 785-790.

14. Kardelen F, Akçurin G, Ertuğ H, Akcurin S, Bircan I. Heart rate variability and circadian variations in type 1 diabetes mellitus. Pediatr Diabetes 2006; 7: 45-50.

15. Jaiswal M, Urbina EM, Wadwa RP, et al. Reduced heart rate variability among youth with type 1 diabetes: the Search CVD study. Diabetes Care 2013; 36: 157-162. 
16. Colhoun HM, Francis DP, Rubens MB, Underwood SR, Fuller JHc. The association of heart-rate variability with cardiovascular risk factors and coronary artery calcification: a study in type 1 diabetic patients and the general population. Diabetes Care 2001; 24: $1108-1114$.

17. Singh JP, Larson MG, O’Donnell CJ, Wilson PF, Tsuji H, LloydJones DM, Levy D. Association of hyperglycemia with reduced heart rate variability (The Framingham Heart Study). Am J Cardiol 2000; 86: 309-312.

18. Schroeder EB, Chambless LE, Liao D, et al. Diabetes, glucose, insulin, and heart rate variability: the Atherosclerosis Risk in Communities (ARIC) study. Diabetes Care 2005; 28: 668-674.

19. Cambri LT, Oliveira FR, Gevaerd MS. Cardiac autonomic modulation in rest and metabolic control in subjects with type 2 diabetes. HU Ver 2008; 34: 115-121.

20. Godoy M, Takakura I, Correa P. The relevance of nonlinear dynamic analysis (Chaos Theory) to predict morbidity and mortality in patients undergoing surgical myocardial revascularization. Arq Ciênc Saúde 2005; 12: 167-171.

21. Ewing DJ, Neilson JM, Shapiro CM, Stewart JA, Reid W. Twenty four hour heart rate variability: effects of posture, sleep, and time of day in healthy controls and comparison with bedside tests of autonomic function in diabetic patients. Br Heart J 1991; 65: 239-244.

22. Brazilian Society of Cardiology/Brazilian Society of Hypertension/ Brazilian Society of Nephrology. VI Brazilian Guidelines for Hypertension. Arq Bras Cardiol 2010; 95: 1-51.

23. Brazilian Association for the Study of Obesity and Metabolic Syndrome. Brazilian guidelines for obesity, 3rd edition. Itapevi, SP, AC Pharmaceuticals, 2009.

24. World Health Organization (WHO). Waist circumference and waist-hip ratio: report of a WHO expert consultation. Geneva, 2011, 39pp.

25. Brazilian Association of Nutrology and Brazilian Society of Parenteral and Enteral Nutrition. Use of bioimpedance for evaluation of body mass. Project guidelines: Brazilian Medical Association and Federal Council of Medicine, 2009.

26. Lukaski H. Methods for the assessment of human body composition: traditional and new. Am J Clin Nutr 1987; 46: 537-556.

27. Matsudo S, Timoteo A, Matsudo V, et al. International physical activity questionnaire (IPAQ): study of validity and reliability in Brazil. Rev Bras Ativ Fís Saúde 2001; 6: 5-18.

28. Vanderlei LC, Silva RA, Pastre CM, Azevedo FM, Godoy MF. Comparison of the Polar S810i monitor and the ECG for the analysis of heart rate variability in the time and frequency domains. Braz J Med Biol Res 2008; 41: 854-859.

29. Vanderlei L, Pastre C, Júnior IF, Godoy M. Geometric indexes of heart rate variability in obese and eutrophic children. Arq Bras Cardiol 2010; 95: 35-40.

30. Niskanen JP, Tarvainen MP, Ranta-aho PO, Karjalainen PA. Software for advanced HRV analysis. Comput Methods Programs Biomed 2004; 76: 73-81.

31. Fronchetti L, Nakamura FY, Aguiar CA, De-Oliveira FR. Indexes of autonomic cardiac regulation in rest and during progressive exercise. Application of the heart rate variability threshold. Rev Port Cien Desp 2006; 6: 21-28.

32. Lima JRP, Oliveira TP, Ferreira-Júnior AJ. Post-exercise cardiovascular autonomic recovery: review of the underlying autonomic mechanisms and clinical and sports relevance. Motric 2012; 8 (Suppl 2): 419-430.
33. Acharya UR, Paul Joseph K, Kannathal N, Lim CM, Suri JS. Heart rate variability: a review. Med Biol Eng Comput 2006; 44: 1031-1051.

34. Menown IB, Davies S, Gupta S, Kalra PR, Lang CC, Morley C, Padmanabhan S. Resting heart rate and outcomes in patients with cardiovascular disease: where do we currently stand? Cardiovasc Ther 2013; 31: 215-223.

35. Palatini P. Elevated heart rate: a "new" cardiovascular risk factor? Prog Cardiovasc Dis 2009; 52: 1-5.

36. Cooney MT, Vartiainen E, Laatikainen T, Juolevi A, Dudina A, Graham IM. Elevated resting heart rate is an independent risk factor for cardiovascular disease in healthy men and women. Am Heart J 2010; 159: 612-619.

37. Stettler C, Bearth A, Allemann S, et al. QTc interval and resting heart rate as long-term predictors of mortality in type 1 and type 2 diabetes mellitus: a 23-year follow-up. Diabetologia 2007; 50: 186-194.

38. Nagaya T, Yoshida H, Takahashi H, Kawai M. Resting heart rate and blood pressure, independent of each other, proportionally raise the risk for type-2 diabetes mellitus. Int J Epidemiol 2010; 39: $215-222$.

39. Tarvainen MP, Laitinen TP, Lipponen JA, Cornforth DJ, Jelinek HF. Cardiac autonomic dysfunction in type 2 diabetes effect of hyperglycemia and disease duration. Front Endocrinol (Lausanne) 2014; 5: 130.

40. Mushtaq MU, Gull S, Abdullah HM, Shahid U, Shad MA, Akram J. Waist circumference, waist-hip ratio and waist-height ratio percentiles and central obesity among Pakistani children aged five to twelve years. BMC Pediatr 2011; 11: 105.

41. Qiao Q, Nyamdorj R. The optimal cutoff values and their performance of waist circumference and waist-to-hip ratio for diagnosing type II diabetes. Eur J Clin Nutr 2010; 64: 23-29.

42. Kotsis V, Stabouli S, Papakatsika S, Rizos Z, Parati G. Mechanisms of obesity-induced hypertension. Hypertens Res 2010; 33: 386-393.

43. Strychar I, Cohn JS, Renier G, et al. Effects of a diet higher in carbohydrate/lower in fat versus lower in carbohydrate/higher in monounsaturated fat on postmeal triglyceride concentrations and other cardiovascular risk factors in type 1 diabetes. Diabetes Care 2009; 32: 1597-1599.

44. Quirk H, Blake H, Tennyson R, Randell TL, Glazebrook C. Physical activity interventions in children and young people with Type 1 diabetes mellitus: a systematic review with meta-analysis. Diabet Med 2014; 31: 1163-1173.

45. Plank J, Köhler G, Rakovac I, et al. Long-term evaluation of a structured outpatient education programme for intensified insulin therapy in patients with type 1 diabetes: a 12-year follow-up. Diabetologia 2004; 47: 1370-1375.

46. Piłaciński S, Zozulińska-Ziółkiewicz D A. Influence of lifestyle on the course of type 1 diabetes mellitus. Arch Med Sci 2014; 10: 124-134.

47. Salem MA, Aboelasrar MA, Elbarbary NS, Elhilaly RA, Refaat YM. Is exercise a therapeutic tool for improvement of cardiovascular risk factors in adolescents with type 1 diabetes mellitus? A randomised controlled trial. Diabetol Metab Syndr 2010; 2: 47.

48. Rachmiel M, Buccino J, Daneman D. Exercise and type 1 diabetes mellitus in youth; review and recommendations. Pediatr Endocrinol Rev 2007; 5: 656-665.

49. Lucini D, Zuccotti GV, Scaramuzza A, Malacarne M, Gervasi F, Pagani M. Exercise might improve cardiovascular autonomic regulation in adolescents with type 1 diabetes. Acta Diabetol 2013; 50: $341-349$. 